\title{
Curcumin-Hydroxypropyl- $\beta$-Cyclodextrin Inclusion Complex Preparation Methods: Effect of Common Solvent Evaporation, Freeze Drying, and pH Shift on Solubility and Stability of Curcumin
}

\author{
Chutima Jantarat*, Pornpak Sirathanarun, Shantika Ratanapongsai, Pawut \\ Watcharakan, Siripa Sunyapong and Adil Wadu \\ School of Pharmacy, Walailak University, Thasala District, Nakhon Si Thammarat 80161, Thailand
}

*For correspondence: Email: chutima.ja@wu.ac.th

Received: 10 May 2014

Revised accepted: 8 July 2014

\begin{abstract}
Purpose: To evaluate the effect of the preparation method on the inclusion complex of curcumin and hydroxypropyl- $\beta$-cyclodextrin (HP- $\beta-C D)$.

Methods: HP- $\beta-C D$ was selected to prepare an inclusion complex with curcumin at a molar ratio of 1:1. The inclusion complexes were prepared using three different methods: common solvent evaporation (CSE), freeze drying (FD), and $\mathrm{pH}$ shift. The inclusion complexes were characterized by differential scanning calorimetry (DSC) and fourier transform infrared (FTIR) spectroscopy. The content, solubility, dissolution, and stability of the complexes were evaluated and compared with curcumin and their physical mixture.

Results: Formation of inclusion complexes was confirmed by DSC and FTIR results. CSE and FD methods gave a high content of curcumin in the inclusion complexes (> $88.39 \%$ ), while $\mathrm{pH}$ shift gave a lower content $(64.04 \%)$. All three methods significantly $(p<0.05)$ increased curcumin solubility (> 276.43-fold). However, higher stability complexes were obtained using CSE and FD methods.

Conclusion: Among the three preparation methods (CSE, FD and $\mathrm{pH}$ shift) used for the inclusion complexes, CSE is the most suitable method for preparation of curcumin-HP- $\beta-C D$ inclusion complex for increased curcumin solubility and stability.
\end{abstract}

Keywords: Curcumin, Cyclodextrin, Inclusion complex, Solubility, Stability, Common solvent evaporation, Freeze drying, $\mathrm{pH}$ shift

Tropical Journal of Pharmaceutical Research is indexed by Science Citation Index (SciSearch), Scopus, International Pharmaceutical Abstract, Chemical Abstracts, Embase, Index Copernicus, EBSCO, African Index Medicus, JournalSeek, Journal Citation Reports/Science Edition, Directory of Open Access Journals (DOAJ), African Journal Online, Bioline International, Open-J-Gate and Pharmacy Abstracts

\section{INTRODUCTION}

Curcumin is a natural yellow compound found in turmeric (Curcuma longa L.). Although, it has shown many excellent pharmacological activities in in vitro experiments such as antioxidant, antiinflammatory, anti-microbial and also anti-tumor activities [1-4], curcumin has not yet been approved for use as a drug due to the very low bioavailability obtained after curcumin oral administration, which is due, in part, to poor solubility $(11 \mathrm{ng} / \mathrm{mL}$ in aqueous buffer, $\mathrm{pH} 5.5$ [5]) and stability ( $\mathrm{t}_{1 / 2}$ of curcumin in PBS pH 7.2, $<10$ min [6]). Many attempts have been made to solve these problems. One of the most popular means is to form an inclusion complex with cyclodextrins (CDs). 
Many types of CDs have been reported to be used for inclusion complex preparation with curcumin, both naturally occurring CDs: $\alpha-, \beta-$, and $y-C D$ and their derivatives such as methyl and hydroxypropyl derivatives of CDs in order to improve either curcumin solubility or stability. In theory, different molecules can be fit in different CDs according to the size of molecule and the size of the CD cavity. For curcumin, it is not yet clear which type of CD would be the best choice to fit with the curcumin molecule. Previous publications have often used $\beta$ - and $y-C D$ and their hydroxypropyl derivatives to prepare inclusion complexes with curcumin [7-10].

Cyclodextrin inclusion complexes can be prepared by several methods such as kneading, common solvent evaporation, co-precipitation and freeze drying methods. For curcumincyclodextrin inclusion complex preparation, two most often used methods are freeze drying and common solvent evaporation. In 2010, Yadav et al reported a novel $\mathrm{pH}$ shift method for curcumincyclodextrin inclusion complex preparation [11].

In this study, we evaluated the effect of the curcumin-cyclodextrin inclusion complex preparation method on the solubility and stability of curcumin. Two commonly used methods: common solvent evaporation and freeze drying methods were studied in comparison with the newer $\mathrm{pH}$ shift method. The content and dissolution of the curcumin inclusion complexes were also studied. At the beginning, we evaluated four types of $C D s$ including three natural $\alpha-, \beta-$, and $\gamma-C D$ and one derivative hydroxypropyl (HP)- $\beta-C D$ on curcumin solubility based on a phase solubility study and selected one $C D$ that gave the best result for preparation of inclusion complexes with curcumin.

\section{EXPERIMENTAL}

\section{Materials}

Curcumin was purchased from Sigma (St. Louis, MO, USA). $\alpha$ - and $y$-Cyclodextrin were obtained from ISP Technologies, Inc. (Wayne, NJ, USA); $\beta$ - and Hydroxypropyl- $\beta$-cyclodextrin were obtained from Wacker Chemie $\mathrm{GmbH}$ (Germany). All solvents used were of either analytical reagent or HPLC grade.

\section{Phase solubility study}

The effect of the type of CDs: $\alpha-C D, \beta-C D, y-C D$, and HP- $\beta-C D$ on the solubility of curcumin was evaluated before selecting one CD that gave the highest effect to prepare inclusion complexes with curcumin. The phase solubility was studied by weighing six different amounts of each $C D$ and dissolved in $1 \mathrm{~mL}$ of distilled water before placing in a 5-mL glass vial to make six different concentrations from zero to nearly reach its solubility (the solubilities of $\alpha-C D, \beta-C D, \gamma-C D$, and HP- $\beta-C D$ are 149.18, 16.30, 178.87, and $357.14 \mathrm{mM}$, respectively [12]). The concentration of CDs prepared were $0,5,10,20,100$, and 140 $\mathrm{mM}$ for $\mathrm{a}-\mathrm{CD}$; and $0,2,4,6,10$, and $15 \mathrm{mM}$ for $\beta-C D$; and $0,5,10,20,100$, and $160 \mathrm{mM}$ for $\mathrm{y}$ $\mathrm{CD}$; and $0,10,50,100,200$, and $340 \mathrm{mM}$ for $\mathrm{HP}-\beta-C D$. Excessive curcumin $(\sim 50 \mathrm{mg})$ was added in each CD solution and stirred for $24 \mathrm{~h}$ at $25 \pm 1{ }^{\circ} \mathrm{C}$ until it reached equilibrium. The solution was filtered through a $0.45 \mu \mathrm{m}$ filter (Millipore, MA, USA) before analyzing the dissolved curcumin using a UV-visible spectroscopy at $430 \mathrm{~nm}$ as described in the section "Quantitation of curcumin". The studies were carried out in triplicate. The relationships between $C D$ concentrations ( $x$-axis) and curcumin concentrations (y-axis) were plotted and the complexation constants were calculated according to the method described by Higuchi and Connors [13,14].

\section{Curcumin-HP- $\beta$-CD inclusion complex preparation}

Curcumin-HP- $\beta-C D$ inclusion complexes were prepared using curcumin and HP- $\beta-C D$ at $a$ molar ratio of $1: 1$ similar in all three inclusion complex preparation methods. For common solvent evaporation, HP- $\beta-C D(1.3800 \mathrm{~g})$ was placed in a $50-\mathrm{mL}$ beaker and $5 \mathrm{~mL}$ of ethanol was added and gently agitated until HP- $\beta-C D$ dissolved. Curcumin $(0.3680 \mathrm{~g})$ was then added and dissolved until a clear solution was obtained. The beaker was placed in a fumehood at room temperature $\left(25 \pm 1{ }^{\circ} \mathrm{C}\right)$ for $24 \mathrm{~h}$ to allow the solvent to gently evaporate. The dried sample was passed through an 80 mesh sieve. The resulting inclusion complex powder was kept in a desiccator at $25 \pm 1{ }^{\circ} \mathrm{C}$ and protected from light.

For freeze drying, HP- $\beta-C D(1.3800 \mathrm{~g})$ was dissolved in $50 \mathrm{~mL}$ of $50 \% \mathrm{v} / \mathrm{v}$ ethanol. Curcumin $(0.3680 \mathrm{~g})$ was added and stirred until a clear solution was obtained. The solution sample was then dried in a Freeze dryer (DFU1200, Tokyo Rikakikai Co., Ltd., Japan). The dried sample was sieved and the resulting inclusion complex sample kept under the same conditions as that prepared by common solvent evaporation.

For $\mathrm{pH}$ shift, the method was modified from that described by Yadav et al [11] HP- $\beta-C D(1.3800$ 
g) was dissolved in $50 \mathrm{~mL}$ of sodium hydroxide $(0.18 \mathrm{M}, \mathrm{pH} \sim 9)$. Curcumin $(0.3680 \mathrm{~g})$ was added and rapidly agitated until a clear solution was obtained (within 1-2 min). The solution $\mathrm{pH}$ was adjusted to ca. 6 with hydrochloric acid. The sample was then dried in a Freeze dryer (DFU1200, Tokyo Rikakikai Co., Ltd., Japan). The dried sample was sieved and the resulting inclusion complex sample kept under the same conditions as those prepared by other inclusion complex preparation methods.

A physical mixture consisting of curcumin and $\mathrm{HP}-\beta-\mathrm{CD}$ in the same ratio as the inclusion complexes was also prepared. Curcumin and HP- $\beta$-CD were placed in a $5-\mathrm{mL}$ glass vial, capped and physically shaken for 5 min to obtain a homogeneous blend. The mixture was sieved and kept under the same conditions as the inclusion complexes.

\section{Inclusion complex characterization}

The inclusion complexes were characterized to confirm the inclusion complex had formed by using differential scanning calorimetry (DSC 822e, Mettler Toledo, Switzerland) and fourier transform infrared (FTIR) spectroscopy (Spectrum one, Perkin-Elmer, USA). In both techniques, the inclusion complexes were studied in comparison with curcumin, HP- $\beta-C D$, and the physical mixture. For DSC, the samples $(2-3 \mathrm{mg})$ were heated from $-10{ }^{\circ} \mathrm{C}$ to $300{ }^{\circ} \mathrm{C}$ using a heat rate of $10^{\circ} \mathrm{C} / \mathrm{min}$. A nitrogen purge of $50 \mathrm{~mL} / \mathrm{min}$ was used in the oven. For FTIR, the samples were prepared as $\mathrm{KBr}$ discs. The scanning range was $400-4000 \mathrm{~cm}^{-1}$ and the resolution was $4 \mathrm{~cm}^{-1}$.

\section{Quantitation of curcumin}

The content of curcumin was quantified by using UV-visible spectroscopy (UV-1800, Shimadzu, Japan) at a wavelength of $430 \mathrm{~nm}$. The analytical method was validated according to $\mathrm{ICH}$ guidelines [15] in terms of specificity, linearity, accuracy and precision. The standard curcumin solution was prepared in ethanol and diluted to the desire concentrations by $50 \% \mathrm{v} / \mathrm{v}$ ethanol. At the wavelength of $430 \mathrm{~nm}$ which is the $\lambda_{\max }$ of curcumin absorption, there was no interference absorption from any CDs: $\alpha-C D, \beta-C D, y-C D$, and HP- $\beta-C D$. The calibration curve of the method was linear $\left(r^{2}>0.99\right)$ in the $1.00-8.00$ $\mathrm{\mu g} / \mathrm{mL}$ range. The recovery was $103.52 \pm 9.33 \%$ and the intra-day precision (RSD) was lower than $1.20 \%$ indicating the high accuracy and precision of the method.
The content of curcumin in the inclusion complexes study

Each inclusion complex (prepared from different methods) containing $10 \mathrm{mg}$ of curcumin (calculated based on the amount of substances added in preparation) was accurately weighed and placed in a $5-\mathrm{mL}$ glass vial. The samples were extracted with $2 \mathrm{~mL}$ of ethanol using an ultrasonic sonicator for $30 \mathrm{~min}$. The solution was filtered through a $45-\mu \mathrm{m}$ filter (Millipore, MA, USA) and the filtrate was diluted with $50 \% \mathrm{v} / \mathrm{v}$ ethanol to obtain a suitable concentration (within the calibration range). The content of curcumin was analyzed by using UV-visible spectroscopy at $430 \mathrm{~nm}$ as described in the section "Quantitation of curcumin". Each sample was carried out in triplicate.

\section{Solubility study}

The solubility of curcumin inclusion complexes was studied in comparison with curcumin in distilled water at $25 \pm 1{ }^{\circ} \mathrm{C}$. The excessive amount of each inclusion complex $(\sim 50 \mathrm{mg})$ and curcumin was separately placed in a $5-\mathrm{mL}$ glass vial containing $1 \mathrm{~mL}$ of distilled water and stirred for $24 \mathrm{~h}$ at $25 \pm 1{ }^{\circ} \mathrm{C}$ until a saturated solution was obtained. The solution was then filtered through a $45-\mu \mathrm{m}$ filter (Millipore, MA, USA) and the filtrate was diluted with $50 \% \mathrm{v} / \mathrm{v}$ ethanol to obtain a suitable concentration. The content of curcumin was analyzed by using UV-visible spectroscopy at $430 \mathrm{~nm}$ as described in the section "Quantitation of curcumin". Each sample was carried out in triplicate.

\section{Dissolution study}

The dissolution of curcumin inclusion complexes was performed to evaluate the curcumin release profiles. The study was performed on the USP dissolution apparatus type II (VK 7010, Varian, USA) using the simulated intestinal fluid (SIF) without enzymes $\left(6.80 \mathrm{~g}\right.$ of $\mathrm{KH}_{2} \mathrm{PO}_{4}$ and $77 \mathrm{~mL}$ of aqueous $\mathrm{NaOH}(0.20 \mathrm{M})$ in $1000 \mathrm{~mL}$ of water, $\mathrm{pH}=6.8$ ) as a dissolution medium. The inclusion complexes containing $25 \mathrm{mg}$ of curcumin (calculated based on the content of curcumin found in the inclusion complexes) were accurately weighed and placed in a vessel containing $500 \mathrm{~mL}$ of SIF. The temperature was controlled at $37 \pm 0.5{ }^{\circ} \mathrm{C}$ and the paddle was set at $75 \mathrm{rpm}$ throughout the study. At fixed time intervals $(3,6,10,15,30,45$, and $60 \mathrm{~min}), 2 \mathrm{~mL}$ aliquots were withdrawn and equal volumes of fresh medium were replaced. The samples were filtered, suitably diluted, and assayed for curcumin content by using UV-visible spectroscopy at $430 \mathrm{~nm}$ as described in the 
section "Quantitation of curcumin". The release profiles of curcumin and the physical mixture were also evaluated for comparison. Each sample was carried out in triplicate.

\section{Stability study}

The stability of the curcumin inclusion complexes was evaluated under accelerated conditions, 40 $\pm 1{ }^{\circ} \mathrm{C}, 75 \pm 5 \% \mathrm{RH}$, for 3 months. The contents of curcumin were analyzed at fixed time intervals $(0,15$, and 90 days) using the procedure described in the section "The content of curcumin in the inclusion complexes study". The stability of the curcumin inclusion complexes were conducted in parallel with curcumin and the physical mixture. Each sample was carried out in triplicate.

\section{Statistical analysis}

The results were processed using Microsoft Excel 2007 software and expressed as mean \pm standard deviations (S.D.). The statistical analyzes were performed using an unpaired, two tailed student t-test. $P<0.05$ was considered statistically significant.

\section{RESULTS}

\section{Phase solubility}

The relationships between the CD and curcumin concentrations are shown in Figure 1. The concentration of curcumin increased with increasing CD concentration. The relationships were linear and the slopes of the plots were between 0 and 1 indicating an $A_{L}$-type of phase solubility according to Higuchi and Connors concepts [13,14]. These results indicate 1:1 curcumin-CD complex formation in all types of CDs studied. The complexation constant curcumin-CD calculated from Eq 1.

$\mathrm{K}_{1: 1}=$ slope $/\left[\mathrm{S}_{\mathrm{o}}(1-\right.$ slope $\left.)\right]$

where $0<$ slope $<1$ and $S_{0}$ is the solubility of curcumin, were 243.46, 731.71, 54.06 and $3116.61 \mathrm{M}^{-1}$ for $\alpha-C D, \beta-C D, \gamma-C D$, and $H P-\beta-$ $C D$, respectively. The result shows that HP- $\beta-C D$ gave the highest effect on solubility of curcumin within the four types of CDs studied. Therefore, HP- $\beta-C D$ was selected to prepare inclusion complexes with curcumin at a molar ratio of $1: 1$ for all three preparation methods.
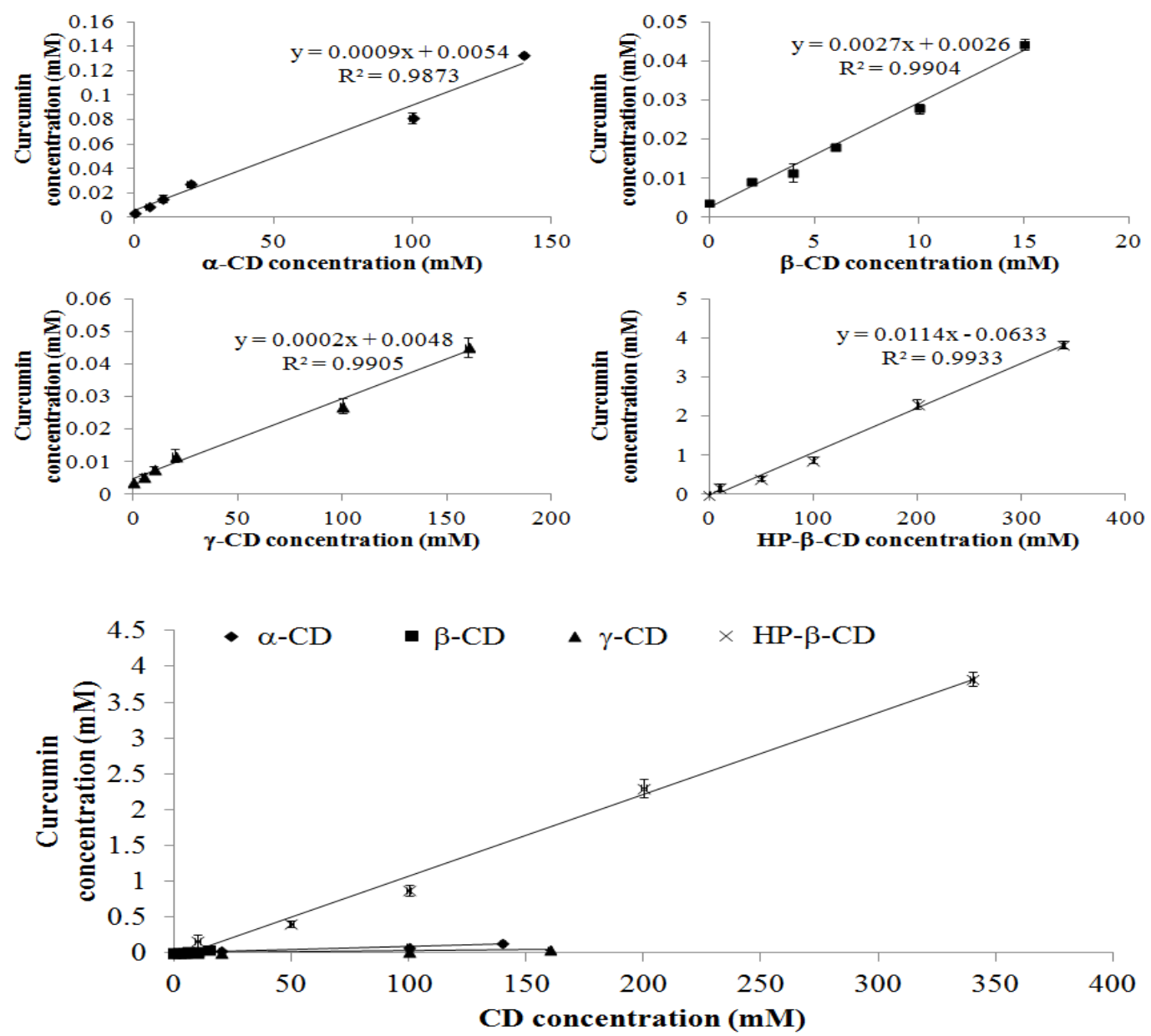

Figure 1: Relationships between curcumin and cyclodextrin concentrations 


\section{Inclusion complex preparation}

The inclusion complexes of curcumin and HP- $\beta$ $C D$ were successfully prepared from all three methods: CSE, FD, and $\mathrm{pH}$ shift. The $\%$ yield of the inclusion complexes obtained from CSE, FD, and $\mathrm{pH}$ shift methods were 97.26, 95.74, and $96.63 \%$, respectively.

\section{Inclusion complex characterization}

Figure $2 \mathrm{~A}$ shows the thermograms of curcumin, $H P-\beta-C D$, the curcumin-HP- $\beta-C D$ physical mixture, and the inclusion complexes prepared from three different methods: CSE, FD, and $\mathrm{pH}$ shift. Curcumin showed one endothermic peak at $176{ }^{\circ} \mathrm{C}$, consistent with its melting point and HP$\beta-C D$ showed a peak at $57{ }^{\circ} \mathrm{C}$ which might be due to the dehydration. The thermograms of the physical mixture and inclusion complexes prepared by CSE and FD methods showed two endothermic peaks which corresponded to the endothermic peak of curcumin and HP- $\beta-C D$. However, the peak around $176{ }^{\circ} \mathrm{C}$ was enormously reduced compared to that of pure curcumin, indicating formation of the inclusion complex. For the inclusion complex prepared by $\mathrm{pH}$ shift, there was no endothermic peak around $176{ }^{\circ} \mathrm{C}$, and a small peak around $50{ }^{\circ} \mathrm{C}$ was found and shifted from the peak corresponded to HP- $\beta-C D$. These results indicate a more complete inclusion complex using the $\mathrm{pH}$ shift method compared to the inclusion complexes prepared by CSE and FD methods.

The FTIR spectra of curcumin, HP- $\beta-C D$, the curcumin-HP- $\beta-C D$ physical mixture, and the inclusion complexes prepared from three different methods: CSE, FD, and $\mathrm{pH}$ shift are shown in Figure 2B. Curcumin showed a main peak at $3436 \mathrm{~cm}^{-1}$, assigned to an $\mathrm{OH}$ stretch. Two other peaks observed at 1627 and $1511 \mathrm{~cm}^{-}$ 1 , are assigned to the aliphatic and aromatic $\mathrm{C}=\mathrm{O}$ stretches, respectively. The peaks at the same wavelength of HP- $\beta-C D$ were found in both the inclusion complexes and the physical mixture. The peaks of curcumin in the region 1800-800 $\mathrm{cm}^{-1}$ were found in both the inclusion complexes and the physical mixture at the same wavelength, but the intensity reduced due to the dilution effect. However, the main characteristic $\mathrm{OH}$ stretch of curcumin $\left(3436 \mathrm{~cm}^{-1}\right)$ was slightly different between those of the inclusion complexes and the physical mixture $\left(3429 \mathrm{~cm}^{-1}\right)$. This might be due to formation of an inclusion complex between curcumin and HP- $\beta-C D$.
Content of curcumin in the inclusion complexes

The contents of curcumin in the inclusion complexes prepared by CSE, FD, and $\mathrm{pH}$ shift methods were $88.39 \pm 0.61,89.02 \pm 0.98$, and $64.04 \pm 1.00 \% \mathrm{w} / \mathrm{w}$, respectively. The inclusion complex preparation method affected the content of curcumin in the inclusion complexes obtained. CSE and FD methods gave a higher content of curcumin, while the $\mathrm{pH}$ shift gave a lower content of curcumin.

\section{Solubility of curcumin inclusion complexes}

Curcumin-HP- $\beta-C D$ inclusion complexes prepared from all three methods can dramatically increase the solubility of curcumin compared to the solubility of pure curcumin (Figure 3 ). The preparation method can affect the solubility of curcumin. The $\mathrm{pH}$ shift method showed the highest effect with the solubility of curcumin increasing about 340 times compared to that of pure curcumin. This might be due to more complete inclusion complex as shown in the DSC study.

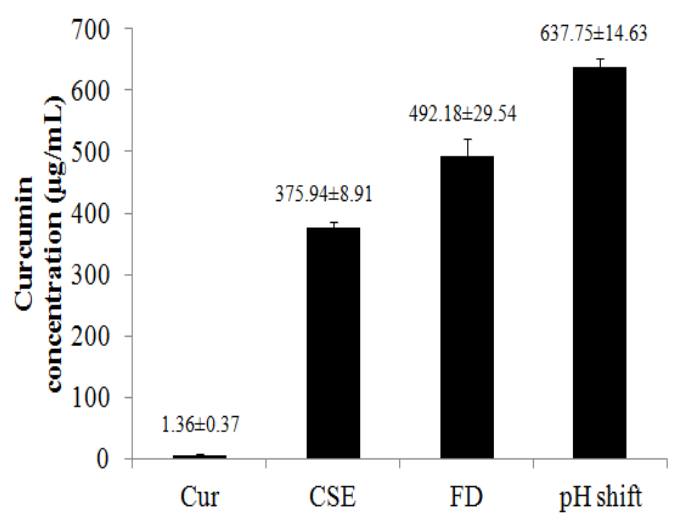

Figure 3: Solubility of curcumin (Cur), curcumin inclusion complexes prepared from different methods: common solvent evaporation (CSE), freeze drying (FD), and $\mathrm{pH}$ shift in distilled water at $25 \pm 1^{\circ} \mathrm{C}$ (mean \pm S.D., $n=3$ )

\section{Dissolution of curcumin inclusion complexes}

Figure 4 shows the cumulative dissolution profiles of pure curcumin, the curcumin-HP- $\beta-C D$ physical mixture, and the inclusion complexes prepared from all three methods. The release of pure curcumin and the physical mixture was very low $(<2 \%)$ at every time point. The inclusion complexes can increase the release of curcumin from low to high in the order $\mathrm{pH}$ shift, CSE, and FD methods. The release of curcumin was very 
A

\section{Temperature $\left({ }^{\circ} \mathrm{C}\right)$}

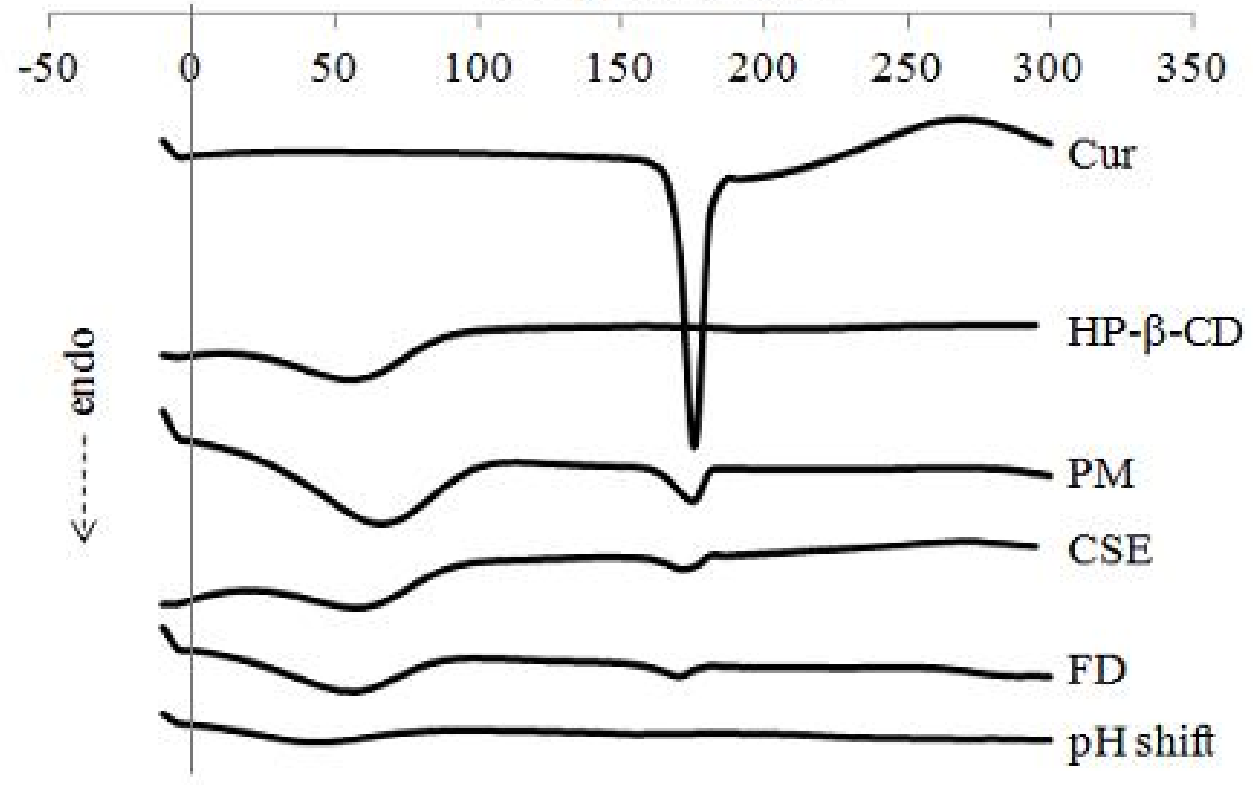

B

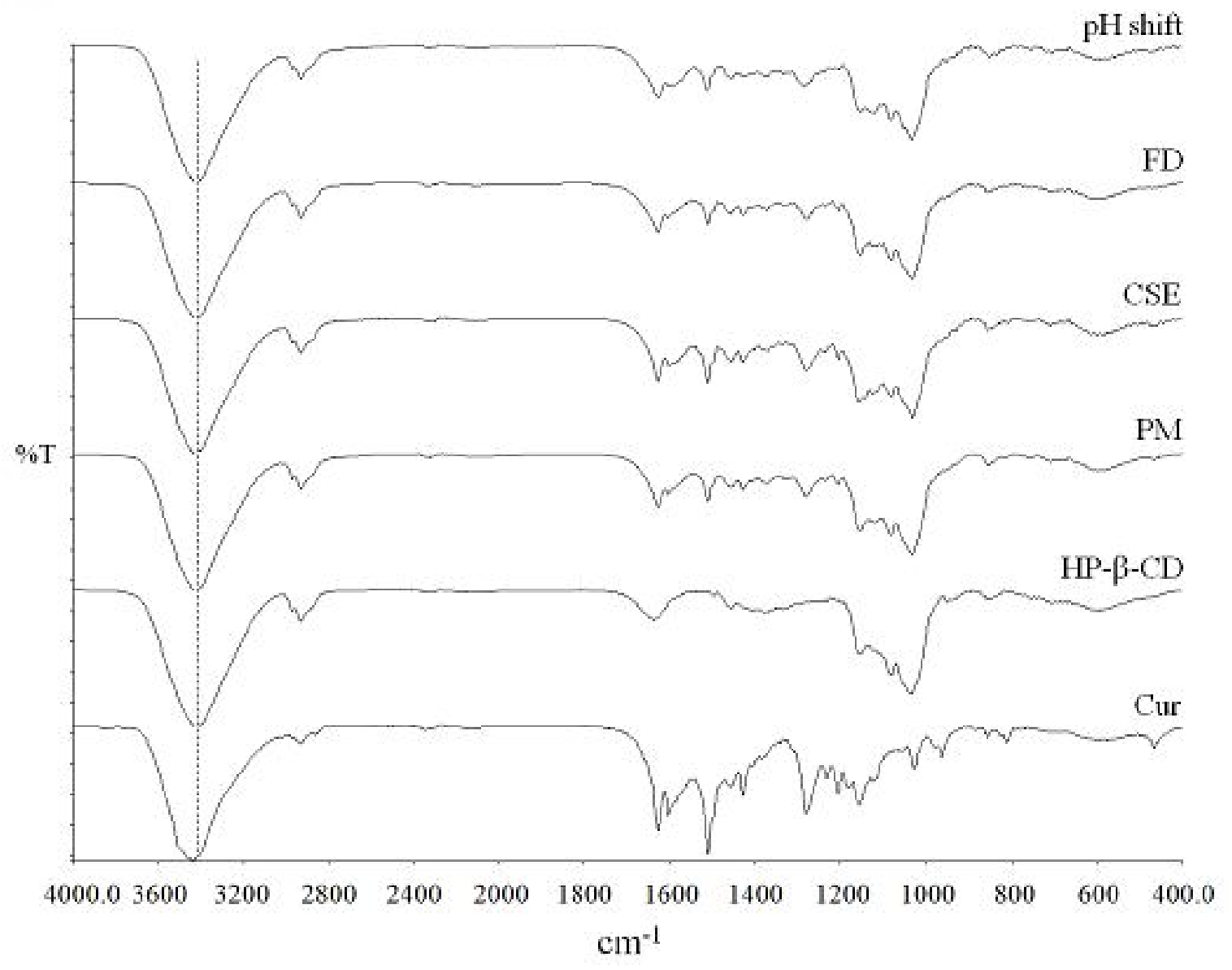

Figure 2: Thermograms (A) and FTIR spectra (B) of curcumin (Cur), HP- $\beta-C D$, curcumin-HP- $\beta-C D$ physical mixture (PM), and inclusion complexes prepared by different methods: common solvent evaporation (CSE), freeze drying (FD), and pH shift 
fast at the beginning of the sampling time point for all three types of inclusion complexes reaching a plateau within 15 min after which the release was quite constant. The $\mathrm{pH}$ shift method gave the release of curcumin as high as $60 \%$. The release of curcumin from CSE $(\sim 20 \%)$ is higher than that of FD method ( $9 \%)$.

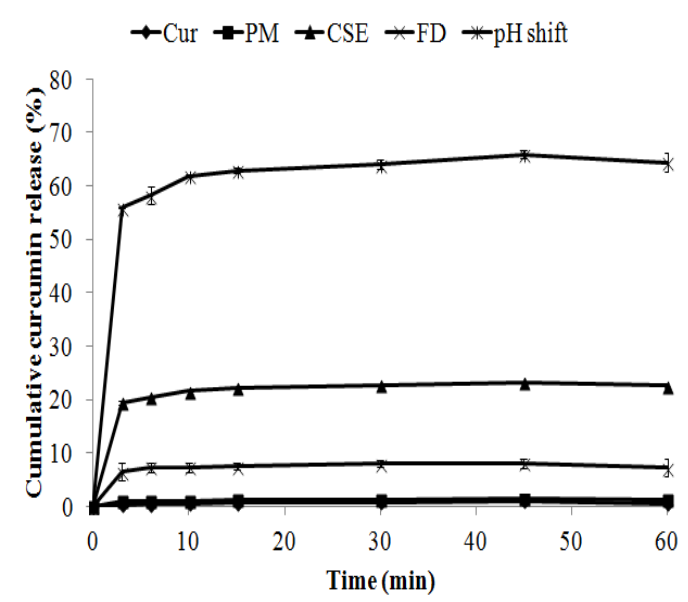

Figure 4: Dissolution profiles of curcumin, curcuminHP- $\beta-C D$ physical mixture (PM), curcumin-HP- $\beta-C D$ inclusion complexes prepared by common solvent evaporation (CSE), freeze drying (FD), and $\mathrm{pH}$ shift methods in SIF at $37 \pm 0.5^{\circ} \mathrm{C}($ mean \pm S.D., $n=3)$

\section{Stability}

From the stability study of the inclusion complexes prepared by different methods compared to pure curcumin and the physical mixture at $40 \pm 1{ }^{\circ} \mathrm{C}, 75 \pm 5 \% \mathrm{RH}$, the results are shown in Figure 5. The content of curcumin and curcumin in the physical mixture gradually decreased as a function of time. The inclusion complexes prepared by CSE and FD methods can delay the reduction of curcumin contents. The content of curcumin in the inclusion complexes prepared by CSE and FD methods were found to be insignificantly different after kept for three months. However, the content of curcumin in the inclusion complex prepared by $\mathrm{pH}$ shift reduced very fast which is significantly different $(p<0.05)$ even after only 14 days. The stability was affected by the inclusion complex preparation method.

\section{DISCUSSION}

Base on phase solubility study, HP- $\beta-C D$ was considered the most suitable type of $C D$ among four types of CDs studied. This might be due to the best fit of curcumin molecule in the cavity of $\beta-C D$ compared with $\alpha-$ or $\gamma-C D$. The cavity of $\beta-$ CD should be able to form inclusion complex with aromatic or heterocyclic compounds [16]. Since the solubility of HP- $\beta-C D$ was about 30 -fold higher than $\beta-C D$ [12], the solubility of the curcumin-HP- $\beta-C D$ inclusion complexes was enormously increased when compared with pure curcumin.

The inclusion complex preparation method affected the content, solubility, dissolution, and stability of the curcumin-HP- $\beta-C D$ inclusion

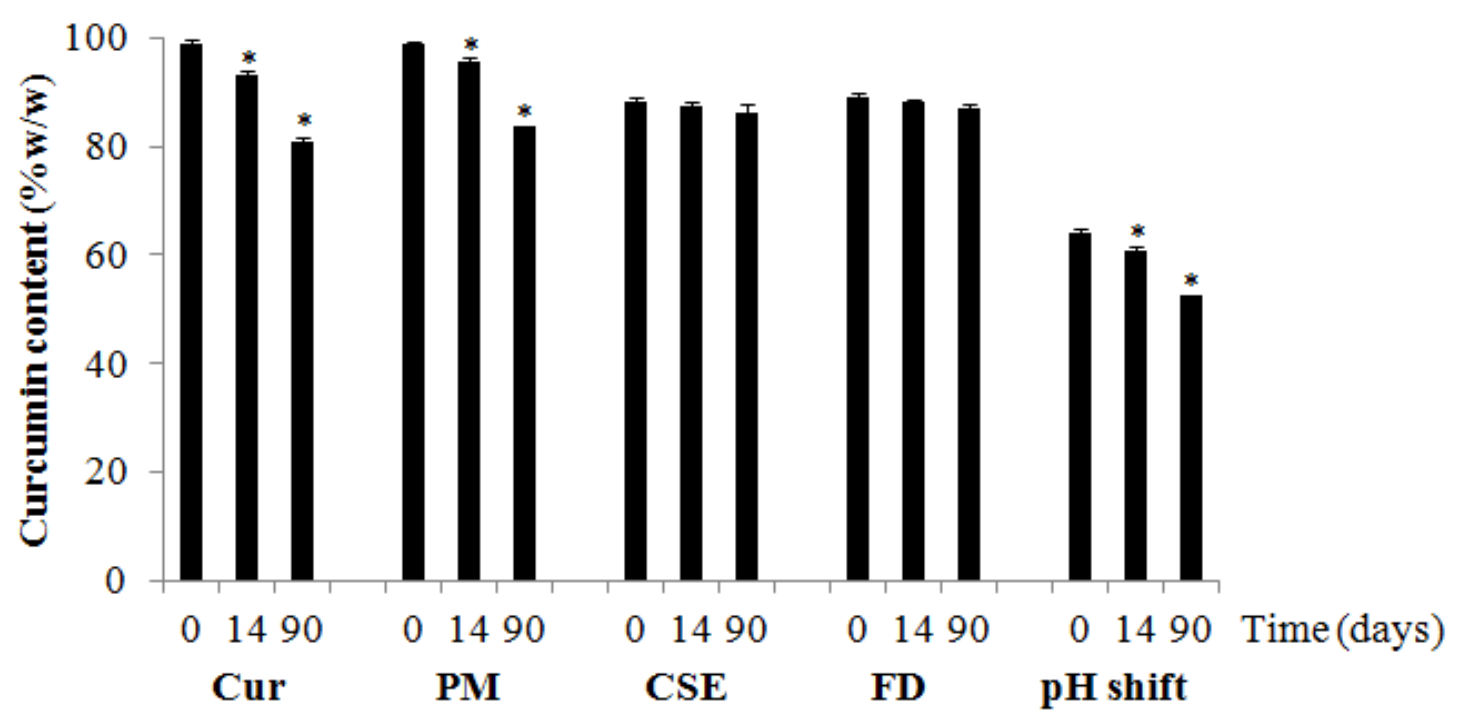

Figure 5: Curcumin content of pure curcumin (Cur), curcumin-HP- $\beta-C D$ physical mixture (PM), inclusion complexes prepared by common solvent evaporation (CSE), freeze drying (FD) and pH shift at $40 \pm 1{ }^{\circ} \mathrm{C}, 75 \pm 5$ $\% \mathrm{RH}$ for 0,14 , and 90 days (mean \pm S.D., $\mathrm{n}=3$ ); * indicates significant difference $(p<0.05)$ of percent of curcumin content compared with at 0 day 
complexes. The highest solubility and dissolution of curcumin inclusion complexes were obtained from $\mathrm{pH}$ shift method, but a high content was obtained from CSE and FD methods, while the best stability was obtained from CSE method. Curcumin is a weak acid compound (the pKa values at 7.8, 8.5, and 9.0 for three acidic protons) and can be dissolved in a basic aqueous medium [5]. The inclusion complex of curcumin-HP- $\beta-C D$ could be then successfully prepared by $\mathrm{pH}$ shift method using an alkaline aqueous medium without any organic cosolvents. Due to the preparation was done in an aqueous medium, the inclusion complex prepared by $\mathrm{pH}$ shift was highly applicable in an aqueous medium: to obtain high solubility and dissolution. From DSC study, the inclusion complex prepared by $\mathrm{pH}$ shift seems to produce a more complete inclusion complex between curcumin and HP- $\beta-C D$. These reasons would support the result that the $\mathrm{pH}$ shift method gave the highest curcumin solubility and dissolution effects compared with CSE and FD methods.

Although curcumin can be dissolved in an alkaline medium, the stability was low due to rapid hydrolytic degradation. Curcumin was reduced about $75 \%$ in PBS pH 7.2 within 5 min [5]. In pH shift method, curcumin must be rapidly dissolved in basic aqueous medium ( $\mathrm{pH}$-9) (within 1-2 $\mathrm{min}$ ) and rapidly adjusted the solution $\mathrm{pH}$ from 9 to 6 to stabilize curcumin before drying. However, some molecule of curcumin might be degraded during preparation and then the curcumin content remaining in the inclusion complex was relatively lower than those prepared by CSE and FD methods. The solution $\mathrm{pH}$ was shifted from 9 to 6 by neutralization reaction. However, due to the rapid process, the reaction might not be completed, led to remain some basic residue in the sample. This would affect the stability of the curcumin inclusion complex prepared by $\mathrm{pH}$ shift methods.

For CSE method, although it was not the best method for curcumin solubility enhancement, it was enormously increased curcumin solubility compared to the solubility of pure curcumin (276.43-fold). The dissolution of the curcumin inclusion complex prepared by CSE method was higher than FD method, and the stability was higher than $\mathrm{pH}$ shift method. Moreover, the CSE was the easiest method among three methods studied in the point of time consuming and instrument use.

\section{CONCLUSION}

The solubility of curcumin can be increased by preparing the inclusion complex with HP- $\beta-C D$ using CSE, FD, or $\mathrm{pH}$ shift methods. The inclusion complex prepared by CSE method afforded curcumin high stability. Among the methods, CSE was the most suitable method for preparation of curcumin inclusion complex with HP- $\beta-C D$. Highly soluble and stable curcumin would be valuable applications in the pharmaceutical, cosmetic and food industries.

\section{ACKNOWLEDGEMENT}

Financial support from the Center for Scientific and Technological Equipments and Institute of Research and Development, Walailak University is acknowledged.

\section{REFERENCES}

1. Naik SR, Thakare VN. Protective effect of curcumin on experimentally induced inflammation, hepatotoxicity and cardiotoxicity in rats: Evidence of its antioxidant property. Exp Toxicol Pathol 2011; 63: 419-431.

2. Hu $P$, Huang $P$, Chen MW. Curcumin reduces Streptococcus mutans biofilm formation by inhibiting sortase A activity. Arch Oral Biol 2013; 58: 13451348.

3. Naksuriya O, Okonogi S, Schiffelers RM, Hennink WE. Curcumin nanoformulations: $A$ review of pharmaceutical properties and preclinical studies and clinical data related to cancer treatment. Biomaterials 2014; 35: 3365-3383.

4. Ahmad W, Kumolosasi E, Jantan I, Jasamai M, Salim E. Modulatory effect of phytoestrogens and curcumin on induction of annexin 1 in human peripheral blood mononuclear cells and their inhibitory effect on secretory phospholipase A2. Trop J Pharm Res 2014; 13(2): 171-177.

5. Tonnesen $\mathrm{HH}$, Masson M, Loftsson $T$. Studies of curcumin and curcuminoids. XXVII. Cyclodextrin complexation: solubility, chemical and photochemical stability. Int J Pharm 2002; 244: 127-135.

6. Wang YJ, Pan MH, Cheng AL, Lin LI, Ho YS, Hsieh CY, Lin JK. Stability of curcumin in buffer solutions and characterization of its degradation products. J Pharm Biomed Anal 1997; 15: 1867-1876.

7. Dhule SS, Penfornis P, Frazier T, Walker R, Feldman J, Tan G, He Jibao, Alb A, John V, Pochampally $R$. Curcumin-loaded $\quad \gamma$-cyclodextrin liposomal nanoparticles as delivery vehicles for osteosarcoma. Nanomedicine 2012; 8: 440-451.

8. Yallapu MM, Jaggi $M$, Chauhan SC. $\beta$-Cyclodextrincurcumin self-assembly enhances curcumin delivery in prostate cancer cells. Colloids Surf B Biointerfaces 2010; 79: 113-125.

9. Mangolim CS, Moriwaki C, Nogueira AC, Sato F, Baesso $M L$, Neto AM, Matioli G. Curcumin- $\beta$-cyclodextrin inclusion complex: Stability, solubility, 
characterization by FT-IR, FT-Raman, X-ray diffraction and photoacoustic spectroscopy, and food application. Food Chem 2014; 153: 361-370.

10. Krishna Mohan PR, Sreelakshmi G, Muraleedharan CV, Joseph R. Water soluble complexes of curcumin with cyclodextrins: characterization by FT-Raman spectroscopy. Vib Spectrosc 2012; 62: 77-84.

11. Yadav VR, Prasad S, Kannappan R, Ravindran J, Chaturvedi MM, Vaahtera L, Parkkinen J, Aggarwal $B B$. Cyclodextrin-complexed curcumin exhibits antiinflammatory and antiproliferative activities superior to those of curcumin through higher cellular uptake. Biochem Pharmacol 2010; 80: 1021-1032.
12. Loftsson T, Duchene D. Cyclodextrins and their pharmaceutical applications. Int J Pharm 2007; 329: 1-11.

13. Higuchi T, Connors KA. Phase solubility techniques. Adv Anal Chem Instrum 1965; 4: 117-212.

14. Kurkov SV, Ukhatskaya EV, Loftsson $T$. Drug/cyclodextrin: beyond inclusion complexation. J Incl Phenom Macrocycl Chem 2011; 69: 297-301.

15. Validation of analytical procedures: text and methodology. International conference on harmonization (ICH) of technical requirements for registration of pharmaceuticals for human use 2005.

16. Del Valle EMM. Cyclodextrins and their uses: a review. Process Biochem 2004; 39: 1033-1046. 